Jozef Gnap - Jana Kupculjakova - Stefania Semanova*

\title{
DETERMINATION OF TIME SAVINGS FOR PASSENGERS BY APPLYING THE PUBLIC PASSENGER TRANSPORT PREFERENCE IN CITIES
}

The paper deals with the issue of delays of public transport vehicles at the signal controlled junctions. Based on the road traffic survey results, the average values of vehicle delays were determined. By using those values, it is possible to define time savings for the vehicles and mainly for passengers that are transported. The time savings were determined based on the relationships and coefficients defined in this paper.

Keywords: public passenger transport, delay time, time savings, preference of public passenger transport

\section{Introduction}

The current trend of growing individual transport can be observed in central areas of Slovak cities where congestion, causing delays of passenger cars, as well as public transport vehicles arises during the peak hours. In the case of foreign cities, the problem of increasing intensity of individual transport is solved by introducing preferential measures for public passenger transport. Those measures contribute to the smooth movement of public transport vehicles on the urban infrastructure, higher speeds and travel time decreases. While maintaining the same interval at a line, the measures may also contribute to a decrease of a number of vehicles dispatched and thus to lower operating costs. This can be reflected in the level of fares, which are one of the important factors influencing the choice of transport means when travelling [1].

By introducing the preferential measures, it is possible to increase punctuality and reliability of the vehicles on lines. This is particularly essential in the case of integrated transport systems where the great emphasis is put on the coordination of individual transport modes [2]. Based on the above mentioned facts, it can be concluded that public passenger transport preference increases the efficiency of public transport and it significantly contributes to the attractiveness and competitiveness of public transport in comparison to individual transport.

Preferential measures can be divided into direct and indirect measures. The direct measures are directly linked to vehicles and roads. In general, they are further divided into physical/spatial measures, preference at signal controlled junctions and integrated measures combining the previous two [3], [4].

\section{Determination of the delay extent of public transport vehicles at signal controlled junctions}

As a great emphasis is nowadays put on the speed of transferring, public passenger transport appears as a slower way of transport and thus less attractive from a passengers' point of view. This is affected by the nature of movement of public transport vehicles, which must stop at the stops; therefore, their average speed is lower compared to passenger cars. Another negative factor affecting the speed of public transport vehicles represents the time losses, a significant part of which is caused by the delays at signal controlled junctions. The extent of such delays increases with increasing intensity of passenger cars and decreasing capacity of junctions [5], [6], [7]. In the case of the road sections with high traffic intensity, the junctions are integrated into the coordinated traffic management with regard to the main directions. However, this does not allow the vehicles, which stop at the stops located at the sections between junctions, to smoothly pass through the road network. As a result, time delays arise [6], [8], [9].

The delay time at a signal controlled junction consists of various forms of delays (Figure 1) [10], [11]:

- Delay due to stopping at a junction $\left(\mathrm{D}_{1}\right)$,

- Delay due to the time needed to approach and exit a junction; it also includes time of stopping at the junction $\left(D_{2}\right)$,

- Travel time delay, which can be considered as the total value of the incurred delay $\left(\mathrm{D}_{3}\right)$.

Figure 1 depicts the differences between the delay times relating to stopping at a junction, approach and exit the junction as well as the overall travel time delay for one vehicle crossing the junction. The desired vehicle path (position in time) and the actual vehicle path are shown in this figure. The desired path represents the situation when a vehicle smoothly passes through a junction at the desired speed without any deceleration i.e. without any delay. The actual path represents the case in which a vehicle crossing a junction must reduce its speed or stop completely and then it must again achieve the required (previous) speed [10], [11]. Thus, the overall vehicle delay $\left(\mathrm{CZ}_{\mathrm{v}}\right)$ can be expressed as the sum of the above mentioned partial delays:

$C Z_{v}=D_{1}+\left(D_{2}-D_{1}\right)+\left(D_{3}-D_{2}\right)$

\footnotetext{
* Jozef Gnap, Jana Kupculjakova, Stefania Semanova

Department of Road and Urban Transport, Faculty of Operation and Economics of Transport and Communications, University of Zilina, Slovakia E-mail: jozef.gnap@fpedas.uniza.sk
} 


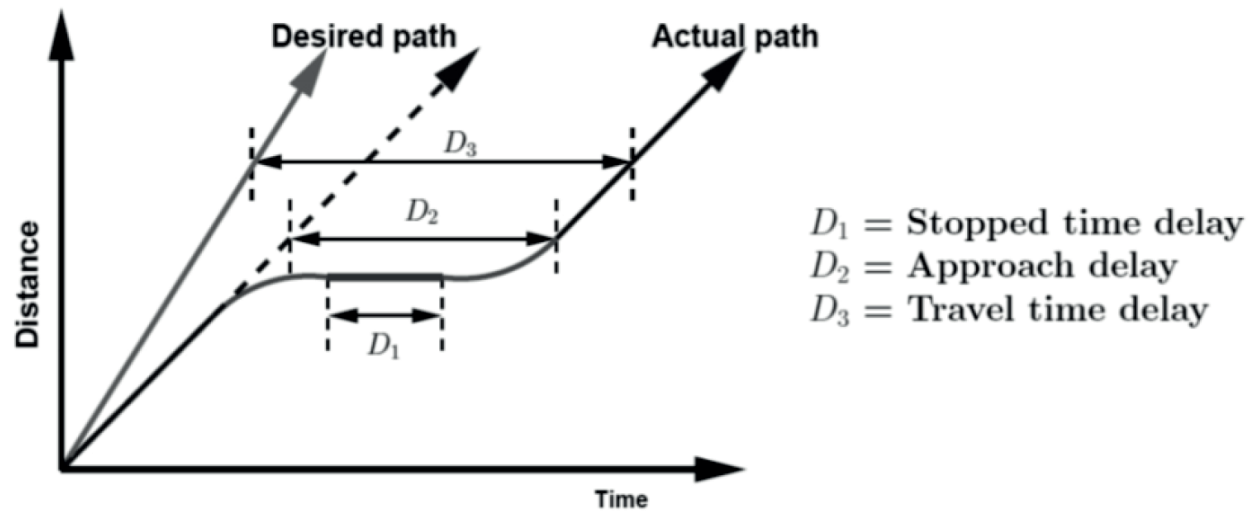

Figure 1 Diagram of the delay time measurement principle, [10], [11]

The extent of individual partial delays is influenced by the driving technique, driver's experience, and vehicle technical condition (this relates mainly to delay time labelled as $\mathrm{D}_{2}$ ). On the other hand, traffic intensity and junction capacity also have an impact on the delay time. As a part of the research work, the extent of vehicle delays was determined by using the road traffic surveys in cities Zilina, Povazska Bystrica, Puchov and Prievidza [12], [13], [14]. The measurements were focused only on determination of the delay time at junctions, labelled as $\mathrm{D}_{1}$.

Taking into account all the above mentioned facts, it is possible to pose the following research questions: "What delay time of public transport vehicles does occur at junctions? Is the delay extent significantly influenced by the traffic intensity on the road network?" Further, we assume that the delay time during the peak hours is at least $10 \%$ higher compared to delays during the off-peak hours.

Time values of delays were determined based on the predetermined methodological procedure during the road traffic surveys. The survey distinguished between the vehicles crossing the junction without delay and the vehicles crossing the junction with a certain delay. Each vehicle that had to stop at the junction was considered as a delayed vehicle. Further, the time intervals between stopping the vehicle at the junction and its moving again was measured and recorded. The difference between those time values represented duration of the vehicle delay. In the case that a vehicle could not cross the junction during a single green phase and it had to stop several times, the delay times were measured unless the vehicle passed through the junction. Therefore, the delay $\mathrm{D}_{1}$ was determined according to the methodological procedure as follows:

$D_{1}=\sum_{i=1}^{n}\left(C R_{i}-C Z_{i}\right)$

where:

$\mathrm{D}_{1}$ - delay due to stopping at a junction,

$\mathrm{CR}$ - time recorded when the vehicle starts to move,

$\mathrm{CZ}$ - time recorded at the moment when the vehicle stops at the junction,

$\mathrm{n}$ - number of vehicle stops at the junction.

A vehicle that slowed down due to the red signalling while approaching the junction but it did not stop was considered as a vehicle crossing the junction without delay.

\section{Evaluation of delays and a definition of the relationships to determine the time savings for passengers}

By carrying out the road traffic surveys, 964 public transport vehicles passing through the signal controlled junctions were evaluated. The data were acquired by using people (counters) placed directly in public transport vehicles, as well as camera records, which were subsequently evaluated. Measured delay times are shown in Figure 2.

The individual points in the graph (Figure 2) depict the delay time measured for each vehicle under consideration. The horizontal solid line represents the average value of delay which was calculated as the arithmetic mean of all measured values. Based on the results, it can be concluded that each vehicle crossing the signal controlled junction must stop for 28 seconds on average. However, it should be noted that the extreme values of delays were also included into the mean value calculation. For this reason, the median was also used to determine the average value. This resulted in the average delay of $20 \mathrm{~s}$ (shown by the dashed line in Figure 2).

The above mentioned average values represent the average vehicle delay when crossing the junction. However, the values do not take into account the change of traffic intensity during a day. Assuming that a higher traffic intensity during the peak hours causes higher vehicle delays, it was necessary to determine the average value separately for each considered time interval. For this reason, the delays were divided according to the periods in which they occurred (peak or off-peak hours). The results are shown in Table 1.

During the peak hours, the average value of delay calculated as the arithmetic mean was at the level of $30 \mathrm{~s}$ and the median represented $23 \mathrm{~s}$. This average value was calculated based on 622 recorded values of delays. During the off-peak hours, the average value of delays was determined at the lower level i.e. 24 $\mathrm{s}$ (arithmetic mean) or $14 \mathrm{~s}$ (median). The calculated results are shown graphically in Figure 3.

Based on the results obtained, it can be stated that the average time of delay increases with the increasing traffic intensity (from $24 \mathrm{~s}$ or $14 \mathrm{~s}$ up to $30 \mathrm{~s}$ or $23 \mathrm{~s}$, respectively). This represents a $25 \%$ increase of delay time. Taking into account median, the increase of the delay time during peak hours represents $64 \%$ in comparison with off-peak hours. 


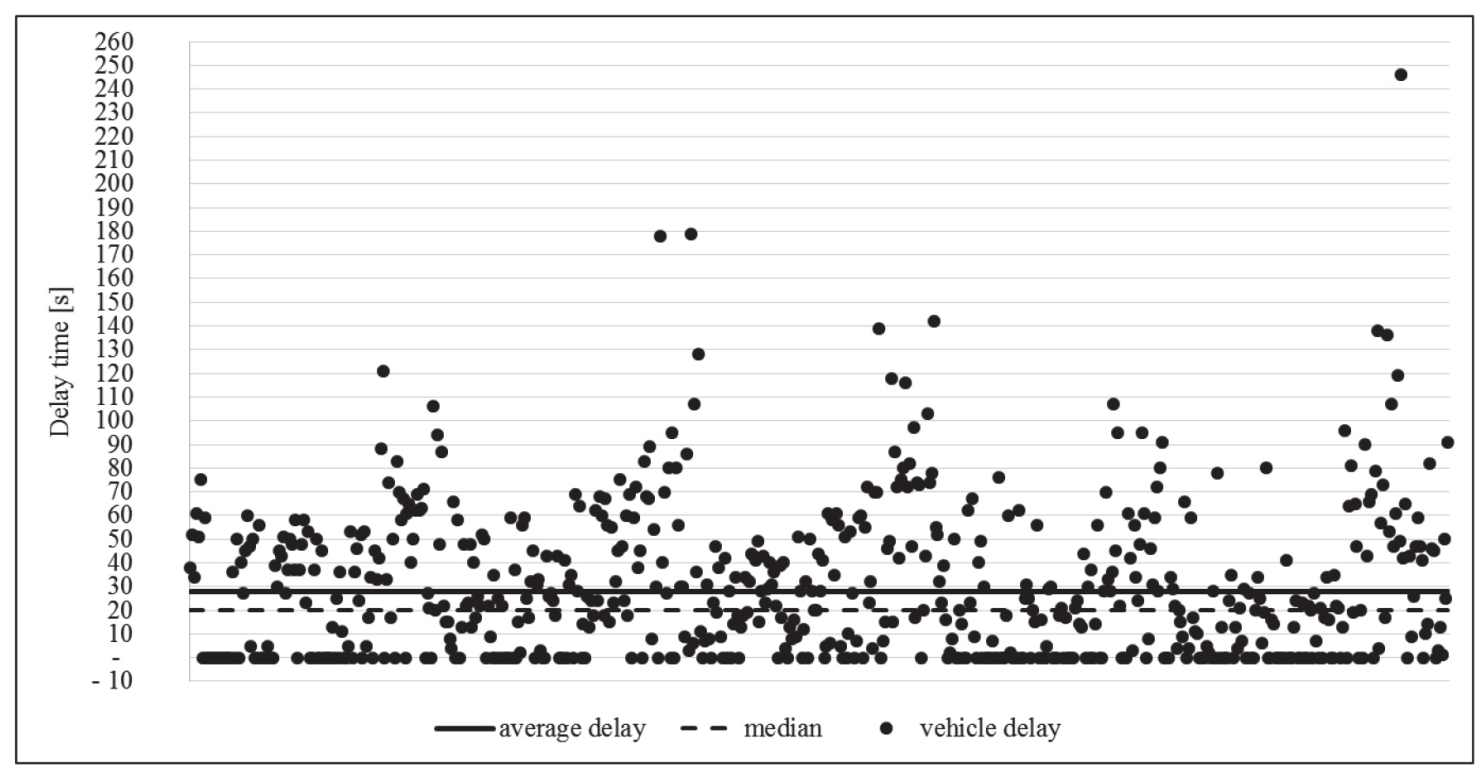

Figure 2 Delay times measured during road traffic surveys

Table 1 Delays of public transport vehicles during daily periods

\begin{tabular}{ccccc}
\hline Measurement & Number of considered values & Arithmetic mean [s] & Median [s] & Mode [s] \\
\hline All values & 964 & 28 & 20 & 0 \\
Peak hours & 622 & 30 & 23 & 0 \\
Off-peak hours & 342 & 24 & 14 & 0 \\
\hline
\end{tabular}

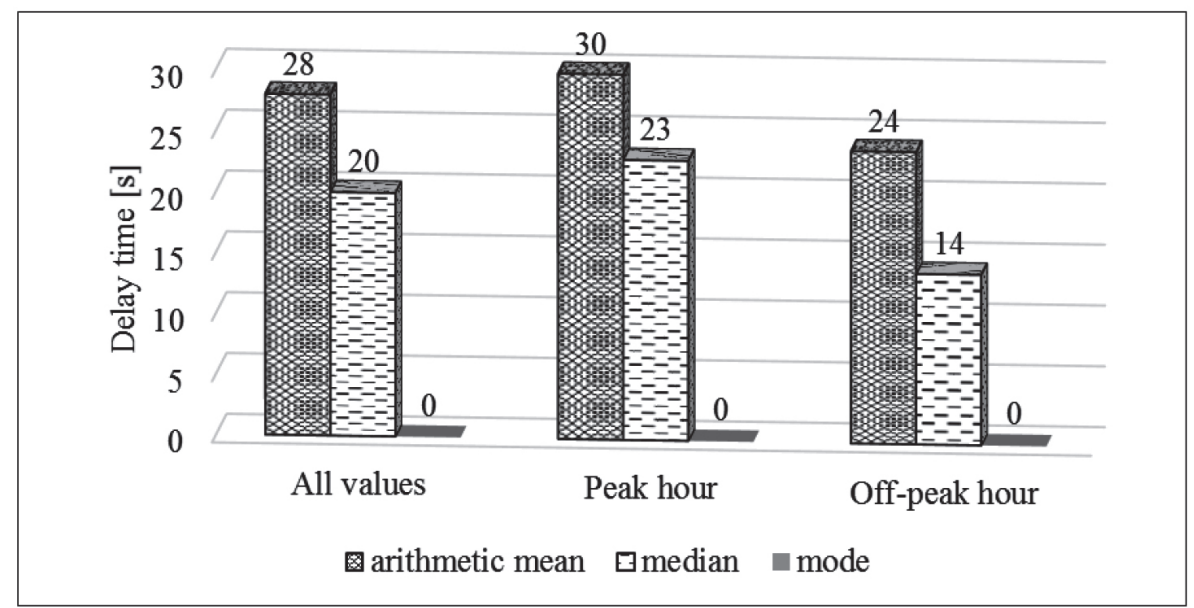

Figure 3 Comparison of delays during the peak and off-peak hours

3.1 Definition of relationships to determine time savings for passengers

Based on the obtained results, it can be concluded that public transport vehicles reach relatively large time losses at signal controlled junctions, in particular during the peak hours. The $25 \%$ increase of vehicle delay time was recorded during peak hours compared to off-peak hours. It is possible to eliminate the mentioned time losses by introducing the public transport preference, which ensures that a public transport vehicle approaching the junction triggers the green signal and then it passes through the junction without delay or only with minimal delay. Let us assume that the delay time $\mathrm{D}_{1}$ can be considered as assumed time savings of one vehicle crossing the junction:

$D_{1}=U_{1}$

$D_{1 d s}=U_{1 d s}$

$D_{1 d s e}=U_{1 d s e}$

If we further assume delay elimination by applying the public transport preference, the assumed time savings of vehicles 
Table 2 Number of vehicles crossing the junction with or without delay and the average delay time

\begin{tabular}{|c|c|c|c|}
\hline Measurement & Delay & Number of considered values & Parameter \\
\hline \multirow{3}{*}{ All values } & without $(0 \mathrm{~s})$ & 291 & Share - $30 \%$ \\
\hline & \multirow{2}{*}{ with } & \multirow{2}{*}{673} & Average delay $40 \mathrm{~s}$ \\
\hline & & & Median $34 \mathrm{~s}$ \\
\hline \multirow{3}{*}{ Peak hours } & without (0s) & 175 & Share - $28 \%$ \\
\hline & \multirow{2}{*}{ with } & \multirow{2}{*}{447} & Average delay $41 \mathrm{~s}$ \\
\hline & & & Median $36 \mathrm{~s}$ \\
\hline \multirow{3}{*}{ Off-peak hours } & without (0s) & 116 & Share - $34 \%$ \\
\hline & \multirow{2}{*}{ with } & \multirow{2}{*}{226} & Average delay $36 \mathrm{~s}$ \\
\hline & & & Median $29 \mathrm{~s}$ \\
\hline
\end{tabular}

crossing the junction during the working days can be determined according to the following formula:

$P U V_{R}=\left(\left(U_{1 d s} \cdot P S_{d s}\right)+\left(U_{1 d s e} \cdot P S_{d s e}\right)\right) \cdot P P D_{R}$

where:

$\mathrm{D}_{1} \quad$ - delay time of one vehicle when crossing the junction,

$\mathrm{U}_{1} \quad$ - time savings of one vehicle crossing the junction regardless of the period during a day,

$\mathrm{PUV}_{\mathrm{R}}$ - assumed time savings of public transport vehicles per annum,

$U_{\text {lds }}$ - time savings of one vehicle crossing the junction during the peak hours,

$\mathrm{PS}_{\mathrm{ds}}$ - number of public transport vehicles during the peak hours per working day,

$\mathrm{U}_{1 \mathrm{dse}}$ - time savings of one vehicle crossing the junction during off-peak hours,

$\mathrm{PS}_{\mathrm{dse}}$ - number of public transport vehicles during the off-peak hours per working day,

$\mathrm{PPD}_{\mathrm{R}}$ - number of working days per annum.

In the case that the values of assumed time savings, divided according to the period during a day (peak and off-peak hours) are not available and the average value of delay/time savings is calculated only based on all measured values, it is possible to determine time savings by using the coefficients, which take into account the daily periods. Coefficients were determined based on the results obtained from the road traffic surveys and thus the assumed time savings value can be calculated according to the following formula:

$P U V_{R}=\left(U_{1} \cdot\left(P S_{d s} \cdot k_{1 d s}+P S_{d s e} \cdot k_{1 d s e}\right)\right) \cdot P P D_{R}$

where:

$\mathrm{k}_{\text {lds }}$ - coefficient of time savings during the peak hours is 1.07 determined by using the arithmetic mean and 1.15 calculated as a median,

$\mathrm{k}_{1 \mathrm{dse}}-$ coefficient of time savings during the off-peak hours is 0.86 when applying the arithmetic mean and 0.7 calculated as a median.

Another possibility of determining the assumed time savings is that the vehicles that are not delayed when crossing the junction are not taken into account into calculations (the delay time $\mathrm{D}_{1}$ represents $0 \mathrm{~s}$ ). This means that every vehicle crossing the junction is considered as delayed when calculating the time savings. However, this does not have to correspond to the real situation, especially during the off-peak hours. The mentioned statement is confirmed by the road traffic surveys, the results of which showed that a part of the vehicles passed through the junction without any delay (Figure 2).

The average values of the delay time, calculated based on the previously mentioned procedure are at the higher level (Table 2), which results in the unrealistic value of time savings. Among the traffic survey results, we selected the vehicles that passed through the junction during the off-peak hours when the traffic intensity is lower. The reason for this was the assumption that the lower delays occur during that period or the vehicles passed through the junction without any delay during a single green phase (cycle).

To eliminate the incurred error, it is possible to use coefficients, the value of which represents the percentage share of vehicles passing through the junction with delay during the peak and off-peak hours. The survey results showed that almost one third of the vehicles crosses the junction without stopping. By using the ascertained average delays and taking into account the vehicles with no delays, it is possible to calculate the assumed time savings according to the following formula:

$$
P U V_{R}=\left(\left(U_{1 d s} \cdot P S_{d s} \cdot p_{d s}\right)+\left(U_{1 d s e} \cdot P S_{d s e} \cdot p_{d s e}\right)\right) \cdot P P D_{R}
$$

where:

$\mathrm{p}_{\mathrm{ds}}$ - coefficient expressing the proportion of vehicles crossing the junction with delay during the peak hours - 0.72 ,

$\mathrm{p}_{\mathrm{dse}}$ - coefficient expressing the proportion of vehicles crossing the junction with delay during the off-peak hours -0.66 .

Based on Equation (7) for determination of the assumed time savings by using the value $U_{1}$ and coefficients of the time savings, it is possible to calculate $\mathrm{PUV}_{\mathrm{R}}$ according to the following formula:

$$
P U V_{R}=\left(U_{1} \cdot\left(P S_{d s} \cdot k_{1 d s} \cdot p_{d s}+P S_{d s e} \cdot k_{1 d s e} \cdot p_{d s e}\right)\right) \cdot P P D_{R}
$$

where the coefficients are as follows:

$\mathrm{k}_{\mathrm{lds}}$ - coefficient of the time savings during the peak hours -1.03 when applying the arithmetic mean and 1.06 calculated as median, 
Table 3 The assumed time savings of vehicles and passengers per a year

\begin{tabular}{|c|c|c|c|c|}
\hline \multirow[b]{2}{*}{ Indicators } & \multicolumn{2}{|c|}{ Public transport vehicles } & \multicolumn{2}{|c|}{ Passengers } \\
\hline & $\begin{array}{l}\text { Arithmetic mean } \\
\text { [hours/year] }\end{array}$ & $\begin{array}{c}\text { Median } \\
\text { [hours/year] }\end{array}$ & $\begin{array}{c}\text { Arithmetic mean } \\
\text { [hours/year] }\end{array}$ & $\begin{array}{c}\text { Median } \\
\text { [hours/year] }\end{array}$ \\
\hline Assumed time savings (6) (10) & 316.7 & 230.6 & 13833.3 & 10361.1 \\
\hline Assumed time savings (7) & 316.6 & 230.6 & 13821.1 & 10361.1 \\
\hline Assumed time savings (8) & 312.0 & 269.2 & 13620.0 & 11863.3 \\
\hline Assumed time savings (9) & 313.2 & 269.2 & 13680.0 & 11871.7 \\
\hline
\end{tabular}

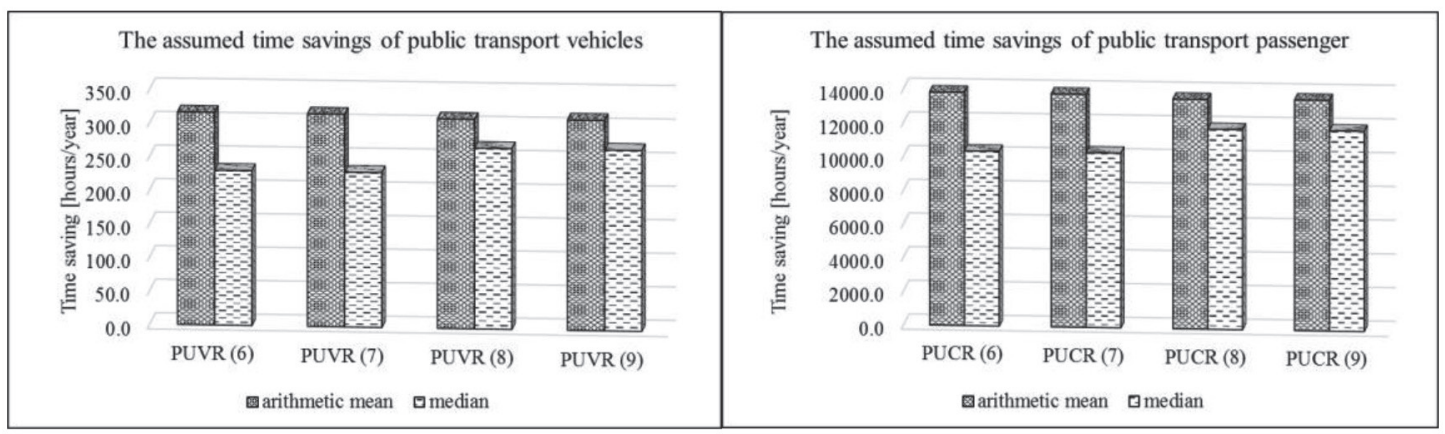

Figure 4 The assumed time savings of vehicles and passengers

$\mathrm{k}_{1 \mathrm{dse}}$ - coefficient of the time savings during the off-peak hours 0.9 when applying the arithmetic mean and 0.8 calculated as median.

At present practice, the determination of the benefit from introducing the preferential measures in public passenger transport usually includes only the calculation of time savings for the vehicles passing through junctions. However, the public transport preference is primarily introduced for current, as well as potential passengers, in order to shorten travel time spent by commuting, travelling to schools etc. The travel time plays an important role in a decision-making process, and therefore, we recommend calculating the time savings with regard to passengers, as well, as follows:

$$
P U C_{R}=\left(\left(U_{1 d s} \cdot P S_{d s} \cdot P C_{d s}\right)+\left(U_{1 d s e} \cdot P S_{d s e} \cdot P C_{d s e}\right)\right) \cdot P P D_{R}
$$

where:

$\mathrm{PUC}_{\mathrm{R}}$ - assumed time savings for passengers per annum,

$\mathrm{PC}_{\mathrm{ds}}$ - average number of passengers in a public transport vehicle during the peak hours per working day,

$\mathrm{PC}_{\mathrm{dse}}$ - average number of passengers in a public transport vehicle during the off-peak hours per working day.

The assumed time savings for passengers can be determined also by using the previous Equations (7), (8) and (9) into which it is necessary to add the average number of passengers.

\subsection{Application of the defined relationships}

The assumed time savings can be calculated by using the mentioned relationships and under consideration of the following assumptions. During the working day, 120 vehicles with the average occupancy of 50 passengers pass through the junction during the peak hours and 40 vehicles with the average occupancy of 20 passengers pass through the junction during the off-peak hours. One year is considered to include 250 working days. The results of time savings are shown in Table 3.

Values of the assumed annual time savings were determined separately for vehicles and passengers. To calculate these values, the relationships defined in the previous section were used. The values are also graphically shown in Figure 4.

\section{Conclusion}

The issue of public transport vehicle delays cannot be considered only as a delay of some vehicle at the junction but it is necessary to perceive the delay time mainly as the time losses of passengers.

Based on the survey results, it can be concluded that each public transport vehicle is delayed for $28 \mathrm{~s}$ on average when passing through one signal controlled junction (or $20 \mathrm{~s}$ if applying a median). However, this delay time does not take into account the traffic intensity changing during the day. For this reason, the average values of delay time during the peak hours ( $30 \mathrm{~s}$ or $23 \mathrm{~s}$ ) and the off-peak hours (24 s or $14 \mathrm{~s}$ ) were also calculated. Furthermore, the assumption that the delay time increases by more than $10 \%$ during the peak hours was confirmed. The delay time during the peak hours increases by $25 \%$ compared to the off-peak hours. When comparing the values calculated by using a median, this increase represents $64 \%$.

If we consider the average delay time as the assumed time savings and we use the relationships defined in this paper for the calculation, the assumed annual time savings for passengers will exceed 10000 hours. Taking into account the average hourly salary, this can result in enormous financial losses. 
By applying preferential measures, it is possible to eliminate delays and thus to provide significant time savings for vehicles, as well as for passengers. However, the preferential measures must be applied scrupulously in order to maximize the effects of public transport preference. The most appropriate method is a combination of spatial preference and preference at signal controlled junctions as well as introduction of the priority in driving for public transport vehicles.

\section{References}

[1] DYDKOWSKI, G., URBANEK, A.: Prices as an Element of Comparative Studies on Peoples Travels in Cities. Communications - Scientific Letters of the University of Zilina, 19(2), 43- 49, 2017.

[2] POLIAK, M., MRNIKOVA, M., JASKIEWICZ, M., JURECKU, R., KACIAKOVA, B.: Public Transport Integration. Communications - Scientific Letters of the University of Zilina, 19(2), 127- 132, 2017.

[3] HAVLENA, O., NOVOTNY, V.: Catalogue of Preference Measures for Public Transport [online]. CVUT, Praha, 2016. Available: http://preferencevhd.info/wp-content/uploads/2016/01/PREFOS-Katalog-preferen\%C4\%8Dn\%C3\%ADchopat\%C5\%99en \%C3\%AD.pdf.

[4] KUPCUlJAKOVA, J.: Possibilities of Ensuring Urban Public Transport Priority. Proceedings of 12th International Conference Transport Systems Telematics (TST'12), Poland, p. 51, 2012.

[5] CERNICKY, L., KALASOVA, A., MIKULSKI, J.: Simulation Software as a Calculation Tool for Traffic Capacity Assessment. Communications - Scientific Letters of the University of Zilina, 18(2), 99-103, 2016.

[6] KAlASOVA, A., CERNICKY, L., KUPCUlJAKOVA, J.: The Impact of Public Transport Priority on the Traffic in the Chosen Part of the City of Zilina. Transport Problems: International Scientific Journal, 9(2), 19-26, 2014.

[7] KAlasova, A., KUPCUlJAKOVA, J.: Microscopic Simulation of Public Transport Priority at Signal Controlled Junction in Zilina City. Journal of Slovak Company for Systematic Integration, 1, p. 8, 2013.

[8] KAlASOVA, A., CERNICKY, L., KUBIKOVA, S.: Microscopic Simulation of Coordinated Route in the City of Zilina. Communications - Scientific Letters of the University of Zilina, 16(2), 46-50, 2014.

[9] KUBIKOVA, S., KALASOVA, A., CERNICKY, L.: Microscopic Simulation of Optimal Use of Communication Network. Communications in Computer and Information Science, 471, 414-423, 2014.

[10] CERNICKY, L.: Time Delay at the Intersection - Comparison of Analytical and Simulation Method. Proceedings of Conference Transport Engineering 2016, Slovakia, 28-39, 2016.

[11] CERNICKY, L., KALASOVA, A., KAPUSTA, J.: Signal Controlled Junctions Calculations in Traffic-Capacity Assessment - Aimsun, OmniTrans, Webster and TP 10/2010 Results Comparison. Transport Problems, 11(1), 121-130, 2016. https://doi. org/10.20858/tp.2016.11.1.12

[12] Completion of Transport Service Plan by Public Passengers Transport in Accordance with the Act of the National Council of the Slovak Republic No. 56/2012 Collection of Laws on Road Transport for City of Puchov - Public Transport Priority in the City of Puchov. Department of Road and Urban Transport, University of Zilina, Zilina, 2016.

[13] Public Transport Priority in the City of Povazska Bystrica. Department of Road and Urban Transport, University of Zilina, Zilina, 2016.

[14] Public Transport Priority of Prievidza City - Optimal Variant. Department of Road and Urban Transport, University of Zilina, Zilina, 2017. 